\title{
Pharmacology of the Bed Nucleus of the Stria Terminalis
}

\author{
Christelle Glangetas $^{1} \cdot$ François Georges $^{2,3}$ (B)
}

Published online: 9 November 2016

(C) Springer International Publishing AG 2016

\begin{abstract}
The bed nucleus of the stria terminalis (BNST) regulates not only stress-related behaviors but also maternal behavior, pain-related behaviors, and reward-driven behavior. Dysfunction of the BNST leads to physiopathological states like anxiety disorder, post-traumatic syndrome disorder, anorexia, or addiction. Thus, a better understanding of the BNST emerges as an important challenge in order to develop innovative therapeutic strategies. Indeed, to improve our knowledge on the BNST, we first need to understand what shapes its activity. The BNST is strongly innervated by multiple inputs (glutamatergic, GABAergic, noradrenergic, dopaminergic, serotoninergic) giving rise to a part of its complexity. Importantly, under specific conditions (stress exposure, drug-withdrawal), endocannabinoid and neuropeptides can orchestrate the activity of the BNST. Here, we give a brief overview of the main pharmacological approaches targeting the BNST to assess the function of classical neurotransmitters and neuromodulators, from a pharmacological point of view through to behavior.
\end{abstract}

Keywords Pharmacology - Bed nucleus of the stria terminalis $\cdot$ Neuromodulators $\cdot$ Endocannabinoid . Catecholamine $\cdot$ Neuropeptides

This article is part of the Topical Collection on Neuropharmacology

François Georges

francois.georges@u-bordeaux.fr

1 Department of Basic Neurosciences, Medical Faculty, University of Geneva, Michel-Servet 1, 1211 Geneva-4, Switzerland

2 Institut des Maladies Neurodégénératives, UMR 5293, University of Bordeaux, 146 Rue Léo Saignat, 33076 Bordeaux, France

3 Institut des Maladies Neurodégénératives, UMR 5293, CNRS, Bordeaux, France

\section{Introduction}

The bed nucleus of the stria terminalis (BNST) belongs to a neuronal network of interconnected limbic regions and is conserved between rodents and humans [1]. For several years, more attention has been directed to understand the role of the BNST in humans [2-4]. The BNST emerges as a critical region that is activated in response to a potential threat or to a stress exposure, in order to develop adaptive strategies. Thus, it gives to the BNST a strong function in the regulation of anxiety and stress exposure [5-9]. Importantly, the BNST has also been presented as key player in motivational and goal directed behavior, through its connections with the reward circuit $[7,8,10-13]$. Dysfunction of the BNST may trigger maladaptive responses to inoffensive cues and physiopathological states such as anxiety disorders or addiction.

The BNST is located posterior to the nucleus accumbens, below the lateral ventricles and surrounding the anterior commissure. The BNST is a heterogeneous structure, not only composed of GABAergic neurons [41, 42] but also contains glutamatergic neurons [7, 41, 43-45]. It can be divided into different subnuclei based on morphological, biochemical, and electrophysiological studies: the antero-medial part of the BNST (amBNST), the antero-lateral part of the BNST (alBNST), the posterior part of the BNST (pBNST), [46-49].

BNST neurons project principally to a fundamental region of the reward system, the ventral tegmental area (VTA), and to a key regulator center of the hypothalamo-pituitary axis, the paraventricular nucleus of the hypothalamus (PVN). In turn, the BNST receives strong glutamatergic inputs mainly arising from the prefrontal cortex, the ventral hippocampus, the basolateral nucleus of the amygdala, and the paraventricular nucleus of the thalamus. In addition, the central nucleus of the amygdala $(\mathrm{CeA})$ and the nucleus accumbens send GABAergic projections to the BNST. 
The activity of BNST neurons is modulated by dopamine (DA) and 5-hydroxytryptamine (5-HT) from the ventral periaqueductal gray region (vPAG)/dorsal raphe (DR) [50, 51] and noradrenaline (NA) coming, from the nucleus of the tractus solitarius (A2) and A1 region [52]. Moreover, the activity of BNST neurons can be modulated by distinct neuropeptides such as corticotropin-releasing factor (CRF), pituitary adenylate cyclase-activating peptide (PACAP), neuropeptide Y, and endocannabinoid under certain circumstances [45, 52]. Altogether, these interconnected structures not only constitute a functional connectome consistent with its role in stress and motivation-associated behaviors but also support the complexity and the multifaceted aspects of the regulation of BNST neurons.

Thus, this review will aim to summarize the main pharmacological studies performed in the BNST based on in vitro, in vivo electrophysiology and behavioral data, in order to give a better view of the intriguing regulation of BNST neuron activity (Table 1).

\section{Glutamatergic Pharmacology of the BNST}

The amBNST receives excitatory inputs primarily from the ventral subiculum of the hippocampus (vSUB) and infralimbic cortex $[42,60,61]$. The lateral part of the BNST mainly received excitatory inputs from the insular cortex [61] and the paraventricular nucleus of the thalamus [62]. Our understanding of the functional role of these pathways mainly stems from local glutamatergic pharmacology studies.

First, activation of metabotropic glutamatergic receptors (mGluR) in the BNST diminishes the glutamatergic transmission. For example, an agonist of the group I mGluR -3,5Dihydroxyphenylglycine (DHPG) decreases the frequency of the miniature excitatory postsynaptic currents (mEPSCs) and triggers long-term depression (LTD) in the BNST $[14,15]$. In addition, bath application of an agonist of the group II of the mGluR (LY354740) diminishes the field response and the EPSC in the BNST [53]. It has been shown that bath application of an agonist of the group III of mGluR (3,4-Dicarboxyphenylglycine (DCPG)) decreases the frequency and the amplitude of the spontaneous excitatory post-synaptic current (sEPSCs) [54]. Together, these studies indicate that activation of $\mathrm{mGluR}$ results in a wide range of inhibitory responses in the BNST that have been associated to anxiety and stress-related behaviors [63].

On the other hand, an infusion of ionotropic glutamatergic antagonist (CNQX ((6-cyano-7-nitroquinoxaline-2,3-dione) + AP5 (2-amino-5-phosphonovaleric acid) reduces the excitatory response in the BNST evoked by the infralimbic cortex stimulation in anesthetized rats [13]. Interestingly, blocking glutamatergic transmission within the BNST in mice (local infusion of CNQX and AP5) can induce anxiolytic effect [8]. In addition, projections from neurons of the BNST to the VTA are crucial not only to behaviors related to reward and motivation but also aversion [7]. One particularly important glutamatergic output of the BNST is the VTA. BNST neurons control the activity of VTA DA neurons; chemical stimulation of the ventral part of the BNST (vBNST) with glutamate infusion increases the bursting activity of VTA DA neurons [11]. Infusing AP5, an N-methyl-D-aspartate (NMDA) receptor antagonist, in the BNST blocks the LTP in BNST neurons projecting to the VTA induced by highfrequency stimulation in the vSUB and the concomitant potentiation of VTA DA neurons [16]. This NMDA-dependent LTP in the BNST enhances the locomotor activity induced by a low threshold of cocaine [16]. The NMDA receptor is a heterotetrameric complex composed of two obligatory GluN1 subunits and two GluN2 and/or GluN3 subunits. The use of NMDA receptor subunit-specific pharmacology have demonstrated a key role of the extrasynaptic populations of GluN2B-containing NMDA receptors in tuning LTP after chronic ethanol exposure [64]. All together, these BNST studies show that glutamate acting on specific NMDA, AMPA, or mGluR receptor subtypes not only can modulate fear and anxiety but also regulate behaviors related to substances of abuse.

\section{GABAergic Pharmacology of the BNST}

The amBNST receives GABAergic innervation mainly from intra-BNST connections (from the oval nucleus), from local interneurons or collaterals [48, 65], and from the central amygdala [60]. First, it has been shown that bath application of an antagonist of GABAA receptor (Picrotoxin) enhances the resting membrane potential of dorsal part of the BNST neurons [66]. Moreover, BNST infusion of an agonist of GABAA receptors (Muscimol) inhibits freezing behavior following an exposure to a predator odor [17]. In addition, anxiety behavior and decrease in social behavior have been noted in animals that had received a GABA synthesis inhibitor (Lallyglycine) in the BNST [18]. An important role attributed to the BNST is the integration of sensory information from a situation perceived as stressfull [67]. Lines of evidence coming from different branches of neuroscience indicate that GABAergic neurotransmission in the BNST is a preferred candidate for modulation of anxiety-related and innatedefensive responses, with evidently clinically relevant effect with benzodiazepine [68]. Together, these data support a strong impact of the GABAergic transmission in the BNST on anxiety-related behaviors.

\section{Monoamine Pharmacology of the BNST}

A characteristic of the BNST is its high contents and diversity of neuromodulators. Indeed, both glutamatergic and 


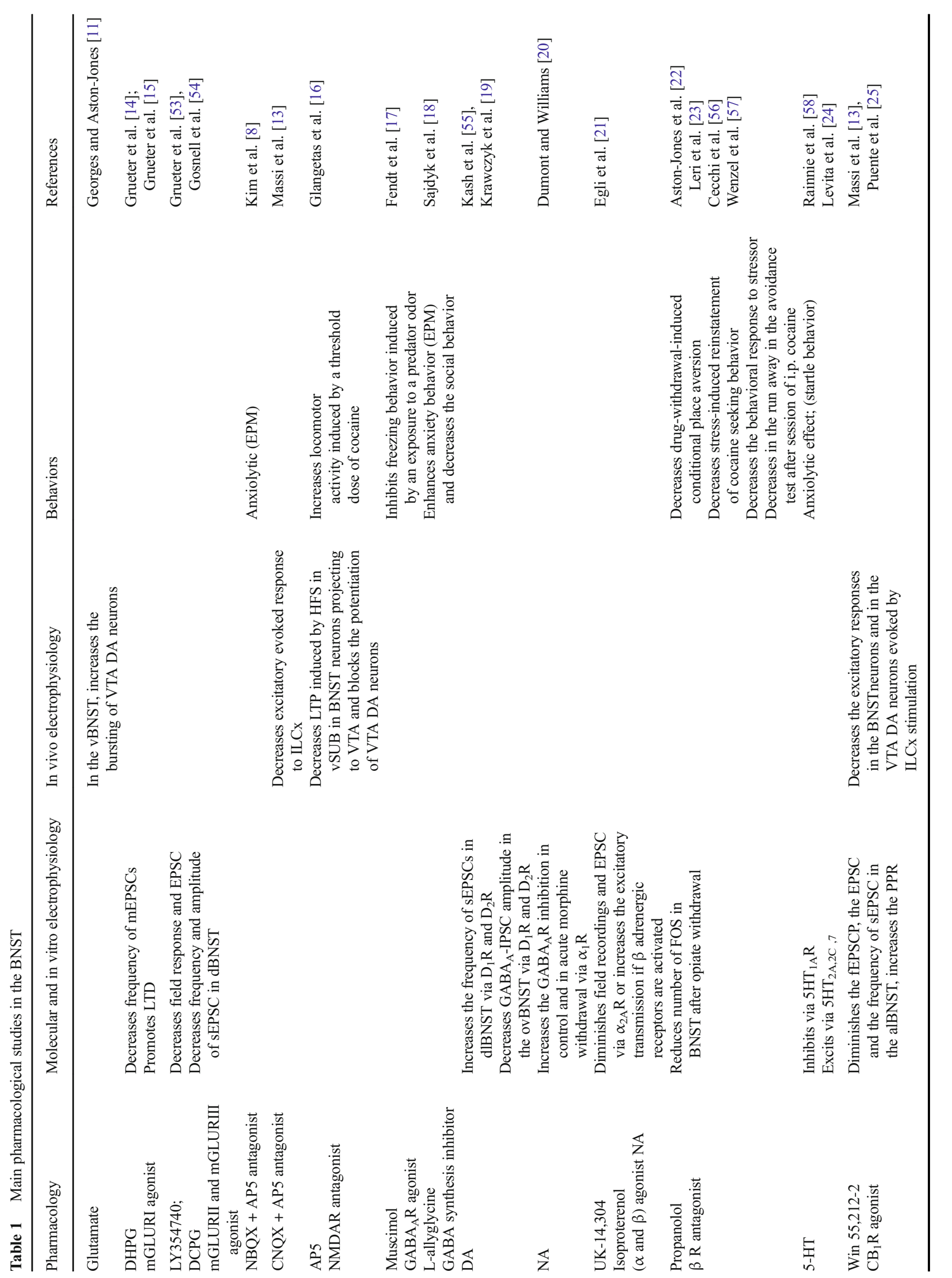




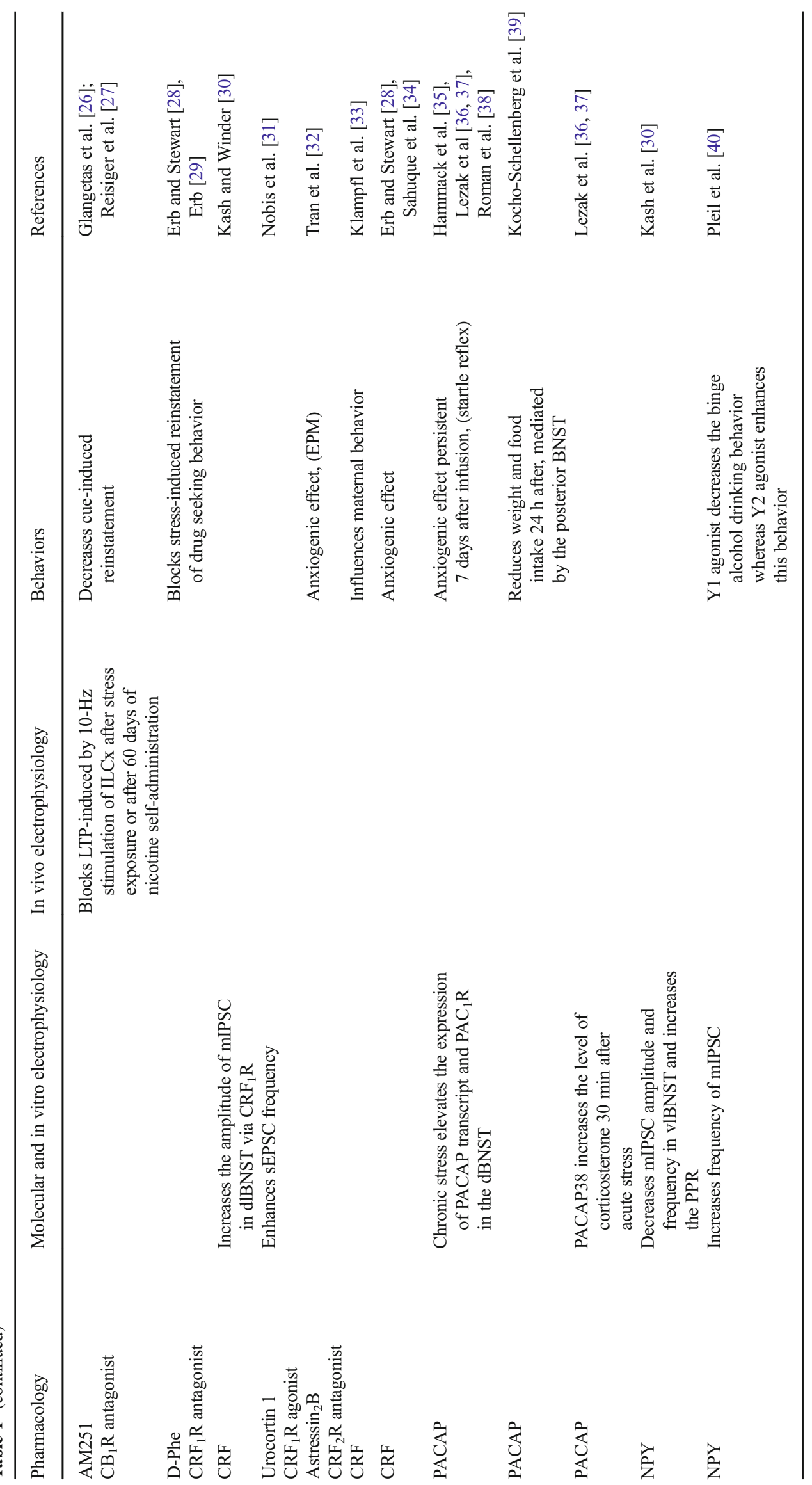


GABAergic transmission within the BNST can be modulated by stress-elicited release of neuromodulators such as monoamines, neuropeptides, and endocannabinoid. Overall, the effects of these neuromodulators in the BNST seem to participate to a multistep control of the autonomic and psychoneuroendocrine impacts of stress.

\section{Noradrenaline}

Noradrenergic fibers arising from the A1 and A2 noradrenergic cell groups (nucleus of the tractus solitarius) [69, 70] mainly project to the vBNST [71]. Threatening or stressful stimuli activate these noradrenergic inputs which thereafter promote the release of NA in the BNST [72, 73]. In addition, noradrenergic system may be activated in response to a reward stimulus. For example, an increase of NA release in the vBNST has been noted after intracranial self-stimulation of the VTA/SNc [74]. NA can act on three different classes of adrenergic receptors: $\alpha, \beta_{1}$, and $\beta_{2}$ receptors (see for more details review [75] ). Intra-BNST infusion of $\beta_{1}$ and $\beta_{2}$ receptor antagonist decreases footshock-induced reinstatement of cocaine seeking behaviors [23] and diminishes drug withdrawal-induced conditional placed aversion [22].

NA can affect both excitatory and inhibitory transmission in the BNST $[20,63,66]$. The action of noradrenaline onto the glutamatergic transmission in the BNST depends on the type of receptor activated. Indeed, it has been demonstrated that application of NA can trigger both enhancement and decrease of the excitatory transmission in the BNST [66]. Notably, bath application of an agonist of the $\alpha 2 \mathrm{~A}$ adrenergic receptors (UK-14,304) decreases the EPSC in the BNST whereas a $\beta$ adrenergic receptor agonist (isoproterenol) increases the excitatory transmission in the dBNST [21]. Furthermore, NA can increase the $\mathrm{GABA}_{\mathrm{A}}$ inhibitory postsynaptic currents (IPSC) in the vlBNST [20]. Thus, these data suggest that noradrenaline can modulate the glutamatergic and the GABAergic transmission in the BNST.

\section{Dopamine}

Dopaminergic fibers originating from the vPAG/DR and the VTA principally innervate the anterodorsolateral part of the BNST [50]. It has been shown that DA bath application increases the frequency of sEPSCs in the dlBNST which was blocked by D1R and D2R antagonists, SCH23390, and sulpiride, respectively [76]. This study suggests that DA enhances the glutamatergic drives onto dlBNST neurons. To extend that work, Krawczyck et al. [19] specify that catecholamines have bidirectional effect onto the oval BNST, a subregion of the anterodorsolateral part of the BNST. In particular, DA diminishes the evoked GABA $A_{A}$ IPSCs through $\mathrm{D}_{2} \mathrm{R}$ whereas NA decreases the AMPAR-EPSCs through the $\alpha_{2}$ adrenergic receptor. Therefore, this result may propose that
DA reduces the inhibitory influence onto oval BNST neurons whereas the NA downregulates the excitatory drive specifically onto them. Thus, DA may regulate differentially anterodorsolateral part of BNST neurons depending on their specific localization.

In the future, better characterization of DA's modulation of the different subnuclei of the alBNST may help to better understand the regional specificity of neurons in the dlBNST and their control by dopamine released from multiple origins. Catecholamines may be an important signal that triggers information related to stressful situations or reward-related situation to the dIBNST.

\section{Serotonin}

It has been described that serotonin (also known as 5hydroxytryptamine (5-HT)) application in the alBNST induces complex neuronal responses. It can drive both excitatory and inhibitory responses $[35,58]$. One hypothesis is that the inhibition of BNST neurons elicited by 5-HT may be triggered by an activation of 5-HT type 1 receptor whereas the excitation of BNST neurons may be mediated through another type of 5-HT receptor, the $5-\mathrm{HT}_{2 \mathrm{~A}}$ or $5-\mathrm{HT}_{7}$. In addition, a recent study highlights a key role of BNST 5-HT2C receptors in promoting anxiety through a specific activation of a subpopulation of CRF neurons [77]. Moreover, bilateral injection of an agonist of the $5-\mathrm{HT}_{1} \mathrm{R}(5-\mathrm{CT})$, in the BNST reduced the acoustic startle responses, which suggests an anxiolytic effect [24]. Thus, activation of the $5 \mathrm{HT}_{1 \mathrm{~A}} \mathrm{R}$ in the $1 \mathrm{BNST}$ may contribute to anxiolytic behavior whereas the activation of the $5 \mathrm{HT}_{2} \mathrm{R}$ may drive anxiogenic effect. Indeed, 5-HT reuptake inhibitor is used as therapeutic tool to treat anxiety trouble disorder. 5-HT is an important neuromodulator that can bidirectionally modulate anxiety depending on the targeted receptor. Additional works may be required to further dissect the action of 5-HT within the BNST.

\section{Endocannabinoid Pharmacology of the BNST}

The endocannabinoid (eCB) system exerts a powerful control onto BNST neurons activity. The eCB system acts as a retrograde signaling by releasing on demand anandamide or 2arachidonoyl-glycerol (2-AG) that targets cannabinoid type 1 receptor $\left(\mathrm{CB}_{1} \mathrm{R}\right)$. Activation of $\mathrm{CB}_{1} \mathrm{R}$ leads to a temporary or prolonged decrease of the neurotransmitter release. $\mathrm{CB}_{1} \mathrm{R}$ have been localized on glutamatergic inputs from medial prefrontal cortex (mPFC) [13, 25] and GABAergic fibers innervating the BNST [25], but have also been proposed to modulate aversive behaviors through its action on noradrenergic transmission in the BNST [78].

The BNST integrates information from stress input pathways, and subsequently regulates both stress output and reward 
pathways $[11,79]$. The endocannabinoid system participates in these functions, since it has been shown that intra-BNST infusion of a $\mathrm{CB}_{1} \mathrm{R}$ agonist, (Win 55,212-2) induces a decrease of excitatory response in BNST neurons evoked by infralimbic cortex (ILCx) electrical stimulation in anesthetized rats [13], which was reversed by i.p. injection of $\mathrm{CB}_{1} \mathrm{R}$ antagonist (SR1416A). In addition, this intra-BNST infusion also decreases ventral tegmental area (VTA) dopamine neurons excitatory evoked activity induced by ILCx stimulation. Moreover, bath application of $\mathrm{CB}_{1} \mathrm{R}$ agonist, (Win 55,212-2), promotes the decrease of fEPSCs, EPSCs and of the frequency of sEPSCs in the alBNST [25]. One of the main functions of the eCB system is to modulate stress response since it acts as an inhibitory tone on the hypothalamo-pituitary axis [80].

We have previously shown that acute restraint stress induced an eCB dependent long term potentiation (LTP) in the amBNST after a $10 \mathrm{~Hz}$ stimulation in the mPFC since it was blocked by intra- BNST infusion of an antagonist of $\mathrm{CB}_{1} \mathrm{R}$, (AM251) [26]. Moreover, $10 \mathrm{~Hz}$ stimulation in the $\mathrm{mPFC}$ also promotes eCB dependent LTP in the amBNST after 60 days of nicotine self-administration in rats [27]. Intra-BNST infusion of AM251 blocked this LTP and decreased the cue-induced reinstatement in these nicotine self-administrated rats.

All together, these data convey a key function of the eCB system in the regulation on BNST neurons activity notably after stress or drug exposure. Further investigations are required to better tackle the role of this complex eCB system in the BNST and their behavioral outcomes.

\section{Neuropeptides Pharmacology of the BNST}

In this part, we will give a brief overview of the different neuropeptides encountered in the BNST and their effects, please for more details (see review [81]).

\section{PACAP}

Pituitary adenylate cyclase activating peptide (PACAP) is a neuropeptide that can be synthetized in two possible isoforms PACAP38 and PACAP27. PACAP has been detected in fibers from the PVN and dorsal vagal complex [82]. The BNST is enriched in PAC1 receptor, which is the main postsynaptic target of PACAP. PACAP infusion in the BNST induces anxiogenic behavior which can persist for up to 7 days after [83]. An increase in the level of corticosterone has been observed after acute PACAP 38 infusion in the BNST [36]. Indeed, repeated stress exposure promotes an increase in PACAP transcript specifically in the dIBNST [37, 83]. In addition, PACAP antagonist infusion in the BNST blocks anxiogenic effect of repeated stress and deficit in novel objet test [38]. In addition, $14 \mathrm{~h}$ after PACAP infusion in the posterior part of the BNST, there is a loss of weight and food intake
$[38,39]$. Thus, these results suggest that PACAP may be released in the BNST after stress exposure to participate to the stress response, and therefore promotes anxiogenic effect. Further electrophysiological studies will be really helpful to understand the neuronal mechanisms of PACAP within the BNST.

\section{CRF}

CRF is a neuropeptide that is mainly produced by the PVN, BNST neurons, or CeA $[46,84]$ which notably participates to the initiation of stress responses through two different type of receptors CRF type: CRF type 1 receptor (CRFR1) and CRF type 2 receptor $R$ (CRFR2) (for more details, see the review [81]). CRF signaling modulates both glutamatergic and GABAergic transmission within BNST and modulates the subpopulation of neurons projecting to the VTA [85]. For example, CRFR1 activation enhances the frequency of sEPSCs in the BNST [31]. In addition, CRF application increases the amplitude of miniature IPSCs in the BNST through CRFR1 [30].

A number of studies have drawn links between CRF signaling in the BNST with several aspects of aversive and anxiogenic behavioral phenotypes. CRFR1 antagonist infused in the BNST block stress-induced reinstatement of drug seeking behavior [28, 86]. CRF infusion in the BNST induces anxiogenic effect mediated by CRFR1 and drives conditional place aversion [34]. However, the effect of CRF depends not only on the type of receptor activated but also on the region of the BNST studied. Indeed, intra-alBNST injection of CRFR2 antagonist also induces an anxiogenic effect [32]. In addition, CRF system within the BNST influences maternal behavior. Notably, it has been shown that CRFR1 activation in the BNST impaired maternal care [33] and participated to the control of autonomic and neuroendocrine function [87].

\section{Neuropeptide $\mathbf{Y}$}

Neuropeptide actions on the BNST are nevertheless much more complex; we do not discuss the action of other neuropeptides in the BNST such as dynorphin, nociceptin, oxytocin, and neurotensin (see, [81] for more details) nor their concomitant actions.

In the BNST, the neuropeptide Y (NPY) can mainly modulate inhibitory GABAergic transmission in the BNST through two distinct receptors: Y1R and Y2R. NPY reduces miniature Inhibitory Postsynaptic Current (mIPSC) amplitude and frequency in the vIBNST via the Y2R [76] More recently, it has been demonstrated that NPY can increase the frequency of mIPSC in the BNST through the Y1R both in mice and monkey [40]. Together, these studies suggest that NPY promote anxiolysis and anti-depressive effects, notably after stress exposure [81, 88, 89]. 
The NPY system in the BNST has also been implicated in addiction. Interestingly, intra-BNST infusion of Y1R agonist decreases binge alcohol drinking behavior, whereas Y2R agonist increases binge drinking behavior. Further investigations on the function of NPY in vivo in the BNST will be helpful and may provide a new pharmaceutical target strategy for anxiety and addiction disorder.

\section{Conclusion}

Thus, understanding how the activity of BNST neurons is regulated represents still a great challenge. Indeed, classical pharmacological approach is an important first step that helps to better tackle these questions. However, as exposed previously, to have a more detail view of the BNST and its complexity, we have also to take into account its different subregions, cell subpopulations, and input specificity. Optogenetic and pharmacogenetic approaches provide good perspectives to further dissect mechanisms and functions of BNST neurons. One other potent question to address is also to define how informations from such different synapses can convey and be integrated at the single cell level in the BNST and how these informations will then be transferred to the VTA and/or to the PVN. The BNST develops powerful plasticity properties under certain circumstances to cope with drastic changes in homeostasis induced by stressful situations or reward experience for example. Further investigations on the BNST and its ability to undergo onto plasticity may be required and would give another alternative approach to treat pathology such as anxiety disorder, anorexia, and addiction.

Acknowledgments This work was supported by grants from the Centre National de la Recherche Scientifique (CNRS), University of Bordeaux, Agence Nationale de la Recherche (ANR-12-BSV4-0022) by LABEX BRAIN ANR-10-LABX-43 and Region Aquitaine. We thank Mrs. P. Gongal (www.theenglishedition.com) for her editorial support.

\section{Compliance with Ethical Standards}

Conflict of Interest On behalf of all authors, the corresponding author states that there is no conflict of interests.

Human and Animal Rights and Informed Consent This article does not contain any studies with human or animal subjects performed by any of the authors.

\section{References}

1. Avery SN, Clauss JA, Blackford JU. The human BNST: functional role in anxiety and addiction. Neuropsychopharmacology. 2016;41(1):12641
2. Mobbs D, Yu R, Rowe JB, Eich H, Feldman Hall O, Dalgleish T. Neural activity associated with monitoring the oscillating threat value of a tarantula. Proc Natl Acad Sci U S A. 2010;107(47): 20582-6.

3. Somerville LH, Whalen PJ, Kelley WM. Human bed nucleus of the stria terminalis indexes hypervigilant threat monitoring. Biol Psychiatry. 2010;68(5):416-24.

4. Avery SN, Clauss JA, Winder DG, Woodward N, Heckers S, Blackford JU. BNST neurocircuitry in humans. NeuroImage. 2014;91:311-23.

5. Dunn JD. Plasma corticosterone responses to electrical stimulation of the bed nucleus of the stria terminalis. Brain Res. 1987;407(2): 327-31.

6. Choi DC, Furay AR, Evanson NK, Ostrander MM, Ulrich-Lai YM, Herman JP. Bed nucleus of the stria terminalis subregions differentially regulate hypothalamic-pituitary-adrenal axis activity: implications for the integration of limbic inputs. J Neurosci. 2007;27(8): 2025-34.

7. Jennings JH, Sparta DR, Stamatakis AM, Ung RL, Pleil KE, Kash TL, et al. Distinct extended amygdala circuits for divergent motivational states. Nature. 2013;496(7444):224-8.

8. Kim SY, Adhikari A, Lee SY, Marshel JH, Kim CK, Mallory CS, et al. Diverging neural pathways assemble a behavioural state from separable features in anxiety. Nature. 2013;496(7444):219-23.

9. Sylvers P, Lilienfeld SO, LaPrairie JL. Differences between trait fear and trait anxiety: implications for psychopathology. Clin Psychol Rev. 2011;31(1):122-37.

10. Carboni E, Silvagni A, Rolando MT, Di Chiara G. Stimulation of in vivo dopamine transmission in the bed nucleus of stria terminalis by reinforcing drugs. J Neurosci. 2000;20(20):RC102.

11. Georges F, Aston-Jones G. Activation of ventral tegmental area cells by the bed nucleus of the stria terminalis: a novel excitatory amino acid input to midbrain dopamine neurons. J Neurosci. 2002;22(12):5173-87.

12. Dumont EC, Mark GP, Mader S, Williams JT. Self-administration enhances excitatory synaptic transmission in the bed nucleus of the stria terminalis. Nat Neurosci. 2005;8(4):413-4.

13. Massi L, Elezgarai I, Puente N, Reguero L, Grandes P, Manzoni OJ, et al. Cannabinoid receptors in the bed nucleus of the stria terminalis control cortical excitation of midbrain dopamine cells in vivo. $\mathrm{J}$ Neurosci. 2008;28(42):10496-508.

14. Grueter BA, Gosnell HB, Olsen CM, Schramm-Sapyta NL, Nekrasova T, Landreth GE, et al. Extracellular-signal regulated kinase 1-dependent metabotropic glutamate receptor 5-induced long-term depression in the bed nucleus of the stria terminalis is disrupted by cocaine administration. J Neurosci. 2006;26(12): 3210-9.

15. Grueter BA, McElligott ZA, Robison AJ, Mathews GC, Winder DG. In vivo metabotropic glutamate receptor 5 (mGluR5) antagonism prevents cocaine-induced disruption of postsynaptically maintained mGluR5-dependent long-term depression. J Neurosci. 2008;28(37):9261-70.

16. Glangetas C, Fois GR, Jalabert M, Lecca S, Valentinova K, Meye FJ, et al. Ventral subiculum stimulation promotes persistent hyperactivity of dopamine neurons and facilitates behavioral effects of cocaine. Cell Rep. 2015;13(10):2287-96.

17. Fendt M, Endres T, Apfelbach R. Temporary inactivation of the bed nucleus of the stria terminalis but not of the amygdala blocks freezing induced by trimethylthiazoline, a component of fox feces. $\mathrm{J}$ Neurosci. 2003;23(1):23-8.

18. Sajdyk T, Johnson P, Fitz S, Shekhar A. Chronic inhibition of GABA synthesis in the bed nucleus of the stria terminalis elicits anxiety-like behavior. J Psychopharmacol. 2008;22(6):633-41.

19. Krawczyk M, de Backer J, Mason X, Jones AA, Dumont EC. Dopamine decreases NMDA currents in the oval bed nucleus of 
the stria terminalis of cocaine self-administering rats. Prog NeuroPsychopharmacol Biol Psychiatry. 2014;51:83-8.

20. Dumont EC, Williams JT. Noradrenaline triggers GABAA inhibition of bed nucleus of the stria terminalis neurons projecting to the ventral tegmental area. J Neurosci. 2004;24(38):8198-204.

21. Egli RE, Kash TL, Choo K, Savchenko V, Matthews RT, Blakely $\mathrm{RD}$, et al. Norepinephrine modulates glutamatergic transmission in the bed nucleus of the stria terminalis. Neuropsychopharmacology. 2005;30(4):657-68.

22. Aston-Jones G, Delfs JM, Druhan J, Zhu Y. The bed nucleus of the stria terminalis. A target site for noradrenergic actions in opiate withdrawal. Ann N Y Acad Sci. 1999;877:486-98.

23. Leri F, Flores J, Rodaros D, Stewart J. Blockade of stress-induced but not cocaine-induced reinstatement by infusion of noradrenergic antagonists into the bed nucleus of the stria terminalis or the central nucleus of the amygdala. J Neurosci. 2002;22(13):5713-8.

24. Levita L, Hammack SE, Mania I, Li XY, Davis M, Rainnie DG. 5hydroxytryptamine1A-like receptor activation in the bed nucleus of the stria terminalis: electrophysiological and behavioral studies. Neuroscience. 2004;128(3):583-96.

25. Puente N, Elezgarai I, Lafourcade M, Reguero L, Marsicano G, Georges F, et al. Localization and function of the cannabinoid $\mathrm{CB} 1$ receptor in the anterolateral bed nucleus of the stria terminalis. PLoS One. 2010;5(1):e 8869.

26. Glangetas C, Girard D, Groc L, Marsicano G, Chaouloff F, Georges F. Stress switches cannabinoid type-1 (CB1) receptor-dependent plasticity from LTD to LTP in the bed nucleus of the stria terminalis. J Neurosci. 2013;33(50):19657-63.

27. Reisiger AR, Kaufling J, Manzoni O, Cador M, Georges F, Caille S. Nicotine self-administration induces CB1-dependent LTP in the bed nucleus of the stria terminalis. J Neurosci. 2014;34(12):428592.

28. Erb S, Stewart J. A role for the bed nucleus of the stria terminalis, but not the amygdala, in the effects of corticotropin-releasing factor on stress-induced reinstatement of cocaine seeking. J Neurosci. 1999;19(20):RC35.

29. Erb S1, Salmaso N, Rodaros D, Stewart J. A role for the CRF-containing pathway from central nucleus of the amygdala to bed nucleus of the stria terminalis in the stress-induced reinstatement of cocaine seeking in rats. Psychopharmacology (Berl). 2001;158(4):360-5.

30. Kash TL, Winder DG. Neuropeptide Y and corticotropin-releasing factor bi-directionally modulate inhibitory synaptic transmission in the bed nucleus of the stria terminalis. Neuropharmacology. 2006;51(5):1013-22.

31. Nobis WP, Kash TL, Silberman Y, Winder DG. Beta-adrenergic receptors enhance excitatory transmission in the bed nucleus of the stria terminalis through a corticotrophin-releasing factor receptor-dependent and cocaine-regulated mechanism. Biol Psychiatry. 2011;69(11):1083-90.

32. Tran L, Schulkin J, Greenwood-Van Meerveld B. Importance of CRF receptor-mediated mechanisms of the bed nucleus of the stria terminalis in the processing of anxiety and pain. Neuropsychopharmacology. 2014;39(11):2633-45.

33. Klampfl SM, Brunton PJ, Bayerl DS, Bosch OJ. CRF-R1 activation in the anterior-dorsal BNST induces maternal neglect in lactating rats via an HPA axis-independent central mechanism. Psychoneuroendocrinology. 2016;64:89-98.

34. Sahuque LL, Kullberg EF, McGeehan AJ, Kinder JR, Hicks MP, Blanton $\mathrm{MG}$, et al. Anxiogenic and aversive effects of corticotropin-releasing factor (CRF) in the bed nucleus of the stria terminalis in the rat: role of CRF receptor subtypes. Psychopharmacology. 2006;186(1):122-32.

35. Hammack SE, Guo JD, Hazra R, Dabrowska J, Myers KM, Rainnie DG. The response of neurons in the bed nucleus of the stria terminalis to serotonin: implications for anxiety. Prog NeuroPsychopharmacol Biol Psychiatry. 2009;33(8):1309-20.
36. Lezak KR, Roelke E, Harris OM, Choi I, Edwards S, Gick N, et al. Pituitary adenylate cyclase-activating polypeptide (PACAP) in the bed nucleus of the stria terminalis (BNST) increases corticosterone in male and female rats. Psychoneuroendocrinology. 2014;45:11-20.

37. Lezak KR, Roman CW, Braas KM, Schutz KC, Falls WA, Schulkin J, et al. Regulation of bed nucleus of the stria terminalis PACAP expression by stress and corticosterone. J Mol Neurosci. 2014;54(3):477-84.

38. Roman CW, Lezak KR, Hartsock MJ, Falls WA, Braas KM, Howard AB, et al. PAC1 receptor antagonism in the bed nucleus of the stria terminalis (BNST) attenuates the endocrine and behavioral consequences of chronic stress. Psychoneuroendocrinology. 2014;47:151-65.

39. Kocho-Schellenberg M, Lezak KR, Harris OM, Roelke E, Gick N, Choi I, et al. PACAP in the BNST produces anorexia and weight loss in male and female rats. Neuropsychopharmacology. 2014;39(7): 1614-23.

40. Pleil KE, Rinker JA, Lowery-Gionta EG, Mazzone CM, McCall NM, Kendra AM, et al. NPY signaling inhibits extended amygdala CRF neurons to suppress binge alcohol drinking. Nat Neurosci. 2015;18(4):545-52.

41. Nguyen AQ, Dela Cruz JA, Sun Y, Holmes TC, Xu X. Genetic cell targeting uncovers specific neuronal types and distinct subregions in the bed nucleus of the stria terminalis. J Comp Neurol. 2016;524(12):2379-99.

42. Cullinan WE, Herman JP, Watson SJ. Ventral subicular interaction with the hypothalamic paraventricular nucleus: evidence for a relay in the bed nucleus of the stria terminalis. J Comp Neurol. 1993;332(1):1-20.

43. Herzog E, Gilchrist J, Gras C, Muzerelle A, Ravassard P, Giros B, et al. Localization of VGLUT3, the vesicular glutamate transporter type 3, in the rat brain. Neuroscience. 2004;123(4):983-1002.

44. Jalabert M, Aston-Jones G, Herzog E, Manzoni O, Georges F. Role of the bed nucleus of the stria terminalis in the control of ventral tegmental area dopamine neurons. Prog Neuro-Psychopharmacol Biol Psychiatry. 2009;33(8):1336-46.

45. Kudo T, Uchigashima M, Miyazaki T, Konno K, Yamasaki M, Yanagawa Y, et al. Three types of neurochemical projection from the bed nucleus of the stria terminalis to the ventral tegmental area in adult mice. J Neurosci. 2012;32(50):18035-46.

46. Ju G, Swanson LW. Studies on the cellular architecture of the bed nuclei of the stria terminalis in the rat: I. Cytoarchitecture. J Comp Neurol. 1989;280(4):587-602.

47. Hammack SE, Mania I, Rainnie DG. Differential expression of intrinsic membrane currents in defined cell types of the anterolateral bed nucleus of the stria terminalis. J Neurophysiol. 2007;98(2): 638-56.

48. Larriva-Sahd J. Histological and cytological study of the bed nuclei of the stria terminalis in adult rat. II. Oval nucleus: extrinsic inputs, cell types, neuropil, and neuronal modules. J Comp Neurol. 2006;497(5):772-807.

49. Rodriguez-Sierra OE, Turesson HK, Pare D. Contrasting distribution of physiological cell types in different regions of the bed nucleus of the stria terminalis. J Neurophysiol. 2013;110(9):2037-49.

50. Hasue RH, Shammah-Lagnado SJ. Origin of the dopaminergic innervation of the central extended amygdala and accumbens shell: a combined retrograde tracing and immunohistochemical study in the rat. J Comp Neurol. 2002;454(1):15-33.

51. Matthews GA, Nieh EH, Vander Weele CM, Halbert SA, Pradhan $\mathrm{RV}$, Yosafat AS, et al. Dorsal raphe dopamine neurons represent the experience of social isolation. Cell. 2016;164(4):617-31.

52. Shin JW, Geerling JC, Loewy AD. Inputs to the ventrolateral bed nucleus of the stria terminalis. J Comp Neurol. 2008;511(5):628-57.

53. Grueter BA, Winder DG. Group II and III metabotropic glutamate receptors suppress excitatory synaptic transmission in the dorsolateral bed nucleus of the stria terminalis. Neuropsychopharmacology. 2005;30(7):1302-11. 
54. Gosnell HB, Silberman Y, Grueter BA, Duvoisin RM, Raber J, Winder DG. mGluR8 modulates excitatory transmission in the bed nucleus of the stria terminalis in a stress-dependent manner. Neuropsychopharmacology. 2011;36(8):1599-607.

55. Kash TL, Baucum AJ, Conrad KL, Colbran RJ, Winder DG. Alcohol exposure alters NMDAR function in the bed nucleus of the stria terminalis. Neuropsychopharmacology. 2009;34(11): 2420-9. Doi:10.1038/npp.2011.40.

56. Cecchi M, Khoshbouei H, Javors M, Morilak DA. Modulatory effects of norepinephrine in the lateral bed nucleus of the stria terminalis on behavioral and neuroendocrine responses to acute stress. Neuroscience. 2002;112(1):13-21.

57. Wenzel JM, Cotten SW, Dominguez HM, Lane JE, Shelton K, Su ZI, Ettenberg A. Noradrenergic $\beta$-receptor antagonism within the central nucleus of the amygdala or bed nucleus of the stria terminalis attenuates the negative/anxiogenic effects of cocaine. J Neurosci. 2014;34(10):3467-74. Doi:10.1523/JNEUROSCI.386113.2014.

58. Rainnie DG. Neurons of the bed nucleus of the stria terminalis (BNST). Electrophysiological properties and their response to serotonin. Ann N Y Acad Sci. 1999;877:695-9.

59. Kash TL, Winder DG. Neuropeptide Y and corticotropinreleasing factor bi-directionally modulate inhibitory synaptic transmission in the bed nucleus of the striaterminalis. Neuropharmacology. 2006;51(5):1013-22.

60. Dong HW, Petrovich GD, Swanson LW. Topography of projections from amygdala to bed nuclei of the stria terminalis. Brain Res Brain Res Rev. 2001;38(1-2):192-246.

61. McDonald AJ, Shammah-Lagnado SJ, Shi C, Davis M. Cortical afferents to the extended amygdala. Ann N Y Acad Sci. 1999;877:309-38

62. Vertes RP, Hoover WB. Projections of the paraventricular and paratenial nuclei of the dorsal midline thalamus in the rat. J Comp Neurol. 2008;508(2):212-37.

63. McElligott ZA, Winder DG. Modulation of glutamatergic synaptic transmission in the bed nucleus of the stria terminalis. Prog NeuroPsychopharmacol Biol Psychiatry. 2009;33(8):1329-35.

64. Wills TA, Klug JR, Silberman Y, Baucum AJ, Weitlauf C, Colbran $\mathrm{RJ}$, et al. GluN2B subunit deletion reveals key role in acute and chronic ethanol sensitivity of glutamate synapses in bed nucleus of the stria terminalis. Proc Natl Acad Sci U S A. 2012;109(5):E278 87.

65. Turesson HK, Rodriguez-Sierra OE, Pare D. Intrinsic connections in the anterior part of the bed nucleus of the stria terminalis. $\mathrm{J}$ Neurophysiol. 2013;109(10):2438-50.

66. Egli RE, Winder DG. Dorsal and ventral distribution of excitable and synaptic properties of neurons of the bed nucleus of the stria terminalis. J Neurophysiol. 2003;90(1):405-14.

67. Daniel SE, Rainnie DG. Stress modulation of opposing circuits in the bed nucleus of the stria terminalis. Neuropsychopharmacology. 2016;41(1):103-25.

68. McGregor IS, Hargreaves GA, Apfelbach R, Hunt GE. Neural correlates of cat odor-induced anxiety in rats: region-specific effects of the benzodiazepine midazolam. J Neurosci. 2004;24(17):4134-44.

69. Forray MI, Gysling K. Role of noradrenergic projections to the bed nucleus of the stria terminalis in the regulation of the hypothalamicpituitary-adrenal axis. Brain Res Brain Res Rev. 2004;47(1-3): 145-60.

70. Forray MI, Gysling K, Andres ME, Bustos G, Araneda S. Medullary noradrenergic neurons projecting to the bed nucleus of the stria terminalis express mRNA for the NMDA-NR1 receptor. Brain Res Bull. 2000;52(3):163-9.

71. Zheng H, Rinaman L. Yohimbine anxiogenesis in the elevated plus maze requires hindbrain noradrenergic neurons that target the anterior ventrolateral bed nucleus of the stria terminalis. Eur J Neurosci. 2013;37(8):1340-9.
72. Pacak K, McCarty R, Palkovits M, Kopin IJ, Goldstein DS. Effects of immobilization on in vivo release of norepinephrine in the bed nucleus of the stria terminalis in conscious rats. Brain Res. 1995;688(1-2):242-6.

73. Zhu L, Onaka T. Involvement of medullary A2 noradrenergic neurons in the activation of oxytocin neurons after conditioned fear stimuli. Eur J Neurosci. 2002;16(11):2186-98.

74. Park J, Bucher ES, Fontillas K, Owesson-White C, Ariansen JL, Carelli RM, et al. Opposing catecholamine changes in the bed nucleus of the stria terminalis during intracranial self-stimulation and its extinction. Biol Psychiatry. 2013;74(1):69-76.

75. Flavin SA, Winder DG. Noradrenergic control of the bed nucleus of the stria terminalis in stress and reward. Neuropharmacology. 2013;70:324-30.

76. Kash TL, Nobis WP, Matthews RT, Winder DG. Dopamine enhances fast excitatory synaptic transmission in the extended amygdala by a CRF-R1-dependent process. J Neurosci. 2008;28(51): 13856-65.

77. Marcinkiewcz CA, Mazzone CM, D'Agostino G, Halladay LR, Hardaway JA, DiBerto JF, et al. Serotonin engages an anxiety and fear-promoting circuit in the extended amygdala. Nature. 2016;537(7618):97-101.

78. Carvalho AF, Reyes AR, Sterling RC, Unterwald E, Van Bockstaele EJ. Contribution of limbic norepinephrine to cannabinoid-induced aversion. Psychopharmacology. 2010;211(4):479-91.

79. Herman JP, Cullinan WE. Neurocircuitry of stress: central control of the hypothalamo-pituitary-adrenocortical axis. Trends Neurosci. 1997;20(2):78-84.

80. Steiner MA, Wotjak CT. Role of the endocannabinoid system in regulation of the hypothalamic-pituitary-adrenocortical axis. Prog Brain Res. 2008;170:397-432.

81. Kash TL, Pleil KE, Marcinkiewcz CA, Lowery-Gionta EG, Crowley N, Mazzone C, et al. Neuropeptide regulation of signaling and behavior in the BNST. Mol Cells. 2015;38(1):1-13.

82. Kozicz T, Vigh S, Arimura A. Immunohistochemical evidence for PACAP and VIP interaction with met-enkephalin and CRF containing neurons in the bed nucleus of the stria terminalis. Ann N Y Acad Sci. 1998;865:523-8.

83. Hammack SE, Cheung J, Rhodes KM, Schutz KC, Falls WA, Braas $\mathrm{KM}$, et al. Chronic stress increases pituitary adenylate cyclaseactivating peptide (PACAP) and brain-derived neurotrophic factor (BDNF) mRNA expression in the bed nucleus of the stria terminalis (BNST): roles for PACAP in anxiety-like behavior. Psychoneuroendocrinology. 2009;34(6):833-43.

84. Sakanaka M, Shibasaki T, Lederis K. Distribution and efferent projections of corticotropin-releasing factor-like immunoreactivity in the rat amygdaloid complex. Brain Res. 1986;382(2):213-38.

85. Silberman Y, Matthews RT, Winder DG. A corticotropin releasing factor pathway for ethanol regulation of the ventral tegmental area in the bed nucleus of the stria terminalis. J Neurosci. 2013;33(3): 950-60.

86. Erb S, Shaham Y, Stewart J. Stress-induced relapse to drug seeking in the rat: role of the bed nucleus of the stria terminalis and amygdala. Stress. 2001;4(4):289-303.

87. Crestani CC, Alves FH, Gomes FV, Resstel LB, Correa FM, Herman JP. Mechanisms in the bed nucleus of the stria terminalis involved in control of autonomic and neuroendocrine functions: a review. Curr Neuropharmacol. 2013;11(2):141-59.

88. Bowers ME, Choi DC, Ressler KJ. Neuropeptide regulation of fear and anxiety: implications of cholecystokinin, endogenous opioids, and neuropeptide Y. Physiol Behav. 2012;107(5):699-710.

89. Tasan RO, Verma D, Wood J, Lach G, Hormer B, de Lima TC, et al. The role of neuropeptide $\mathrm{Y}$ in fear conditioning and extinction. Neuropeptides. 2016;55:111-26. 